Information Management and Business Review

Vol. 5, No. 8, pp. 394-400, Aug 2013 (ISSN 2220-3796)

\title{
Analysis of Risk using Value at Risk (VaR) After Crisis in 2008 Study in Stocks of Bank Mandiri, Bank BRI and Bank BNI in 2009-2011
}

\author{
*Hasna Fadhila, Nora Amelda Rizal \\ Institute Management Telkom, Bandung, Indonesia \\ *asna.fadhila@yahoo.com
}

\begin{abstract}
Value at Risk (VaR) is a tool to predict the greater loss less than the certain confidence level over a period of time. Value at Risk Historical Simulation produce reliable value of VaR because of the historical data and measure the skewness of the observe data. So, Value at Risk well used by investors to determine the risk to be faced on their investment. To calculate VAR it is better to use maximum likelihood, which has been considered for estimating from historical data and also available for estimating nonlinear model. It is also a mathematic function that can approximate return. From the maximum likelihood function with normal distribution, we can draw the normal curve at one tail test. This research conducted to calculate Value at Risk using maximum likelihood. The normal curve will be compared with data return at each bank (Bank Mandiri, Bank BRI and Bank BNI). Empirical results demonstrated that Bank BNI in 2009, Bank BRI in 2010 and Bank BNI in 2011, had less value of VaR by historical simulation in each year. It is concluded that by using maximum likelihood method in the estimation of VaR, has certain appropriates compared with the normal curve.
\end{abstract}

Keywords: Value at Risk, Historical Simulation, Maximum Likelihood Method, Normal Distribution

\section{Introduction}

Investment is a postponement of present consumption to get future consumption. When cash was used to buy some investment such as stock, bond or the other securities, investor will expect to get more cash; this is what we called with expected return. This is also the same, as we want to invest cash in a bank, the investor not only get a big opportunity but also will get a complex risk. Losses could no longer be attributed only to bad government policies and lack of stringent supervision. The need for an improved risk management, especially for financial organizations, became clear. After Lehman Brother's collapsing, US got a difficult condition that trigger crisis of economy in US and global finance in the world included the Bank industry in Indonesia. This crisis causing among other things: the interest rates increasing rapidly, threat to the inflation and stopping credits of investor. This condition affect to bank's performance. In October 2008, there were three big banks in Indonesia, Bank Mandiri, Bank BRI and Bank BNI proposing to assist liquidity from the government for 5 billion Rupiah's or 520 million dollars each to fulfill the commitment of credit. Those assets based on governments fund that save in the Central Bank of Indonesia. From many measurements of risk, one of the most accurate measurements is Value at Risk (VaR) which was popularized by Morgan in 1994. VaR can be used to not only determine the operational risk that was done by operational leverage but also market risk and credit risk. According to Christoffersen et al (2001), VaR measures should satisfy an efficient VaR condition that has been tested by various methodologies. Krause (2003) documented the benefit that VaR is that it is easily and intuitively understood by non-specialist, it can address all types of risks such as market risk, operational risk and financial risk in a single framework and it can be used to set risk limits, to decide allocation of capital and to know which risks that must reduce. The conventional methods used to estimate Value at Risk (VaR) include Historical Simulation, Variance-Covariance and Monte Carlo simulation method. Sartono \& Setiawan (2006) developed the idea of applying VaR historical simulation by historical data; in other word, the value of VaR is more accurate if it is compared by VaR Variance-Covariance. The measurement of VaR using skewness is better than VaR using normal assumption because VaR using skewness produce bigger value of VaR. (Surya \& Situngkir, 2006). Because of these reasons, the measurement of VaR that is used in this research is a historical simulation method. 


\section{Literature Review}

Value at Risk: Jorion (2007) documented Value at Risk summarizes the worst loss over the specific period with a certain confidence level. Krause (2003) defined Value at Risk provide a single number summarizing the total risk such as market risk, operational risk and financial risk. Value at Risk has become risk measurement that used by corporate treasurers and fund managers of financial institutions. Bank regulators also use VaR in determining the capital a bank is required to keep for the risks it is bearing. (Hull, 2012). Jorion (2007) proposed that oone of the conventional method used to estimate Value at Risk is historical simulation method approach. This is a nonparametric method that does not require the distribution of risk factors. This method is easy to implement if historical data have been collected of the selected stocks. However, Sartono \& Setiawan (2006) developed the idea of applying VaR historical simulation using actual historical data, in other word the value of VaR is more accurate if be compared by VaR Variance-Covariance. The measurement of VaR using skewness is better than VaR using normal assumption because VaR using skewness produce bigger value of VaR. (Surya \& Situngkir, 2006)

Maximum Likelihood method: Hull (2012) Maximum likelihood have been considering for the historical data estimation. It involves choosing values for the parameters such as $\mu$ and $\sigma$ that maximize the chance of the data occurring. According to Danielsson (2011) there are many techniques available for estimating nonlinear models, but the most common method is maximum likelihood method (ML). The main idea behind ML is the sample data of the observation that has distribution model and make them become the assumption model that could generate the observed data. In other words, ML estimation (MLE) finds the parameters that maximize the probability (or likelihood) of observing the sample data.

\section{Methodology}

Data: This research subject comprised daily data from the Indonesian stock market, including Bank Mandiri, Bank BRI and Bank BNI, with the data period span from January 1, 2009, to December 31, 2011, and the estimation period span from January 1, 2009, to December 31, 2010, and forecast period span from January 1, 2009, to December 31, 2011. Data of this study is taken from www.yahoofinance.com.

Assessment Methods for VaR Models: Suppose that the instrument is a stock and that the measurement horizon is 1 day. Returns are measured from the end of the preceding day, denoted by the subscript $t-1$, to the end of the current day, denoted by $\mathrm{t}$.

$R_{i}=\frac{P_{t}-P_{t-1}}{P_{t-1}}$

Standard deviation shows how much variation or dispersion exists from the average. High standard deviation indicates that the data points are spread out over large range of value. Standard deviation measure is calculated as follows:

$$
\sqrt{\sigma^{2}}=\sum_{i=1}^{n}\left(R_{j i}-E\left(R_{j}\right)\right)^{2} \cdot P_{r_{i}}
$$

where $\sqrt{\sigma^{2}}$ is varians return, $\mathrm{E}(\mathrm{R})$ is expected return, to the end of the current return, denote by $R_{i}$, to the end of the current probability of return, denote by $P_{r_{i}}$ and ${ }_{j}$ is kind of stock. Take for instance, a 99 percent confidence of level, or $\mathrm{c}=0.99$. VaR then is the cutoff loss such that the probability of experiencing a greater loss is less than 1 percent.

$$
\operatorname{VaR}(X)=W_{0} \times \alpha \times \sigma \times \sqrt{t}
$$

where $W_{o}$ is initial investment, $\alpha$ is confidence level, $\sigma$ is volatility and $t$ is holding period.

This maximization problem can be solved analytically by differentiating the likelihood function with respect to $\mu$ and $\sigma$. Setting the likelihood function equal to zero gives the estimators:

$$
\begin{gathered}
\mu_{M L}=\frac{1}{T} \sum_{t=1}^{T} x_{t} \\
\sigma_{M L}=\frac{1}{T} \sum_{t=1}^{T}\left(x_{t}-\mu_{M L}\right)^{2}
\end{gathered}
$$

where $\mu_{M L}$ is mean likelihood function, $\sigma^{2}{ }_{M L}$ is variance likelihood function, $T$ is number of observation and $x$ is the observation. Next is to estimate the Parameter of Maximum likelihood method

$$
p_{\text {value }}=\frac{v_{1}}{W_{T}}
$$


where $v_{1}$ is variance and $W_{T}$ is initial investment.

Skewness is a measure of the asymmetry of the probability distribution of a real valued random variable, coefficient of skewness is given by:

$$
S k=\frac{\mu-M o}{\sigma}
$$

where $S k$ is coefficient of skewness, $\mu$ is mean, $M o$ is modus and $\sigma$ is standard deviation.

\section{Results and Discussion}

When calculating VaR in this study, with a 99 percent confidence level, the probability of experiencing a greater loss is less than 1 percent. Equation (3-3) is used to estimate the parameter (Wo, $\alpha, \sigma, \sqrt{t}$ ) for VaR forecasting. These parameter values are used to calculate VaR forecasting of the index return at Bank Mandiri, Bank BRI and Bank BNI in 2008 to 2010. The result of parameter estimation for historical simulation model in different future markets is shown in Table 1.

Table 1: Indicator and Value at Risk in 2009-2011

\begin{tabular}{llllllll}
\hline Name of Bank & Stock Price & $\mathbf{p}$ & T & op & VaR 2009 & VaR 2010 & VaR 2011 \\
\hline Bank Mandiri & Rp1.000 & 0.01 & 200 & 2 & Rp54,72 & Rp60,62 & Rp114,88 \\
Bank BRI & Rp1.000 & 0.01 & 200 & 2 & Rp75,40 & Rp48,20 & Rp98,73 \\
Bank BNI & Rp1.000 & 0.01 & 200 & 2 & Rp45,99 & Rp53,74 & Rp83,97 \\
\hline
\end{tabular}

For example if someone invest in the amount of 1 lot (500 thread of stock) at Bank BRI in 2009 with the assumption of a thread of stock is Rp1.000, it means that the asset is Rp500.000 (500 thread x Rp1.000). The risk that will be faced by that assumption is Rp75, 40. The cutoff loss such that the probability of experiencing has a greater loss less than 1 percent is Rp37.699 (500 thread x Rp75, 40). Figure 1, 2 and 3 show the VaR derived by historical simulation method given maximum tolerable loss of $1 \%$ for Bank Mandiri, Bank BRI and Bank BNI.

Figure 1: VaR estimated by historical simulation for Bank Mandiri, Bank BRI and Bank BNI in 2009
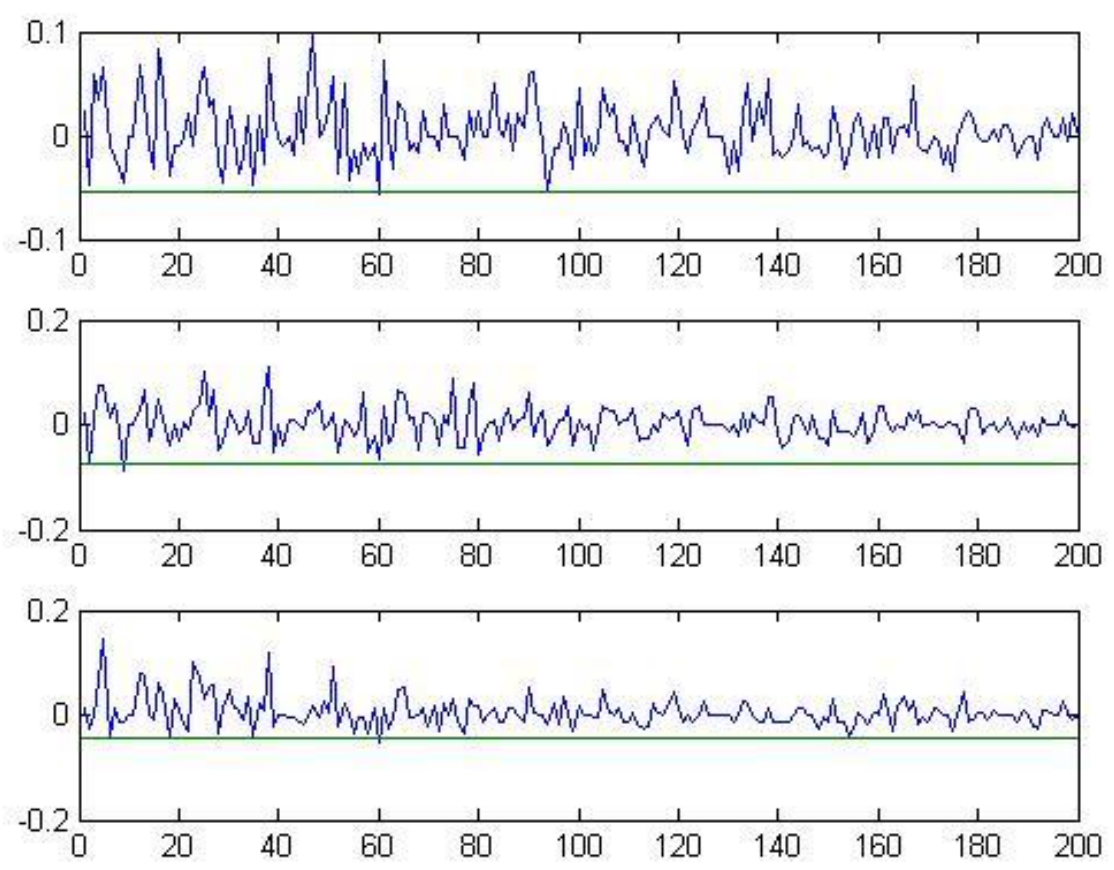
Figure 2: VaR estimated by historical simulation for Bank Mandiri, Bank BRI and Bank BNI in 2010
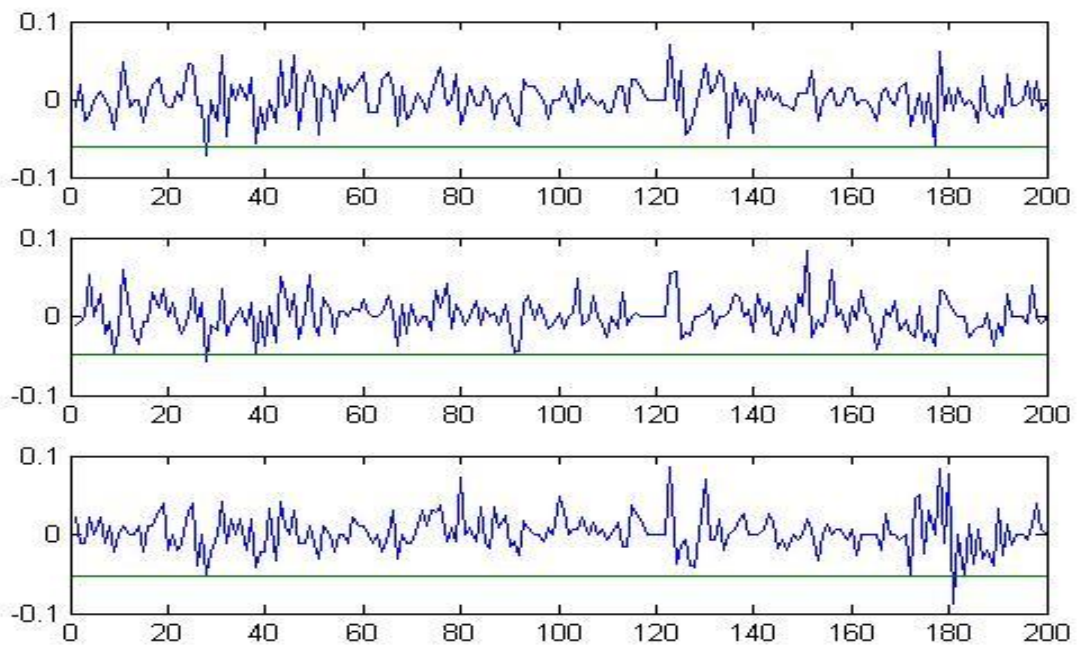

Figure 3: VaR estimated by historical simulation for Bank Mandiri, Bank BRI and Bank BNI in 2011
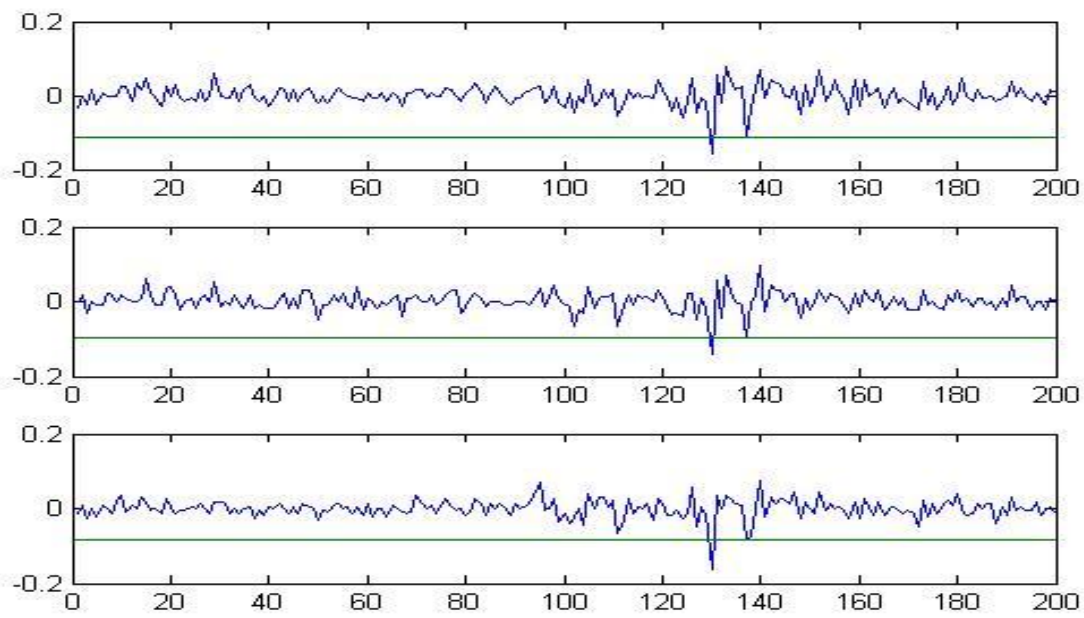

The result of the maximum likelihood method is the parameter such as $\mu, \sigma$ and p-value are shown in Table 2 . These parameter values are used to make likelihood function at Bank Mandiri, Bank BRI and Bank BNI in 2009 to 2011.

Table 2: Parameter Maximum Likelihood Method in 2009-2011

\begin{tabular}{llllllllll}
\hline Name of Bank & Mean & \multicolumn{9}{c}{ Variance } & \multicolumn{1}{c}{ p-value } \\
\hline & 200 & 201 & 201 & 200 & 201 & 201 & 2009 & 2010 & 2011 \\
Bank Mandiri & 9 & 0 & 1 & 9 & 0 & 1 & & & \\
& 0.00 & 0.00 & 0.00 & 0.18 & 0.09 & 0.05 & 0.0002 & 0.0001 & 0.0001 \\
Bank BRI & 40 & 09 & 02 & 23 & 35 & 73 & 023 & 677 & 494 \\
& 0.00 & 0.00 & 0.00 & 0.21 & 0.18 & 0.05 & 0.0002 & 0.0001 & 0.0001 \\
Bank BNI & 28 & 11 & 12 & 65 & 12 & 14 & 099 & 757 & 459 \\
& 0.00 & 0.00 & 0 & 0.08 & 0.09 & 0.02 & 0.0002 & 0.0001 & 0.0001 \\
& 51 & 33 & & 02 & 70 & 46 & 119 & 492 & 492 \\
\hline
\end{tabular}


According the parameter that shown in Table 2, we can draw the function of maximum likelihood at normal distribution in figure 4,5 and 6. Maximum likelihood function is the mathematic function that approximate data return in Bank Mandiri, Bank BRI and Bank BNI at 2009-2011. To know the parameter has the significant level with the assumption model, so we calculating by p-value. The result was further compared using $\alpha$ (0.01), the historical simulation for all 3 stock markets shows the p-value were lower than $\alpha(0.01)$, which displays the significant level with the assumption model. From this maximum likelihood function, we will see the skewness based on frequency for every value of the data.

Figure 4: Maximum Likelihood Function Bank Mandiri, Bank BRI and Bank BNI in 2009
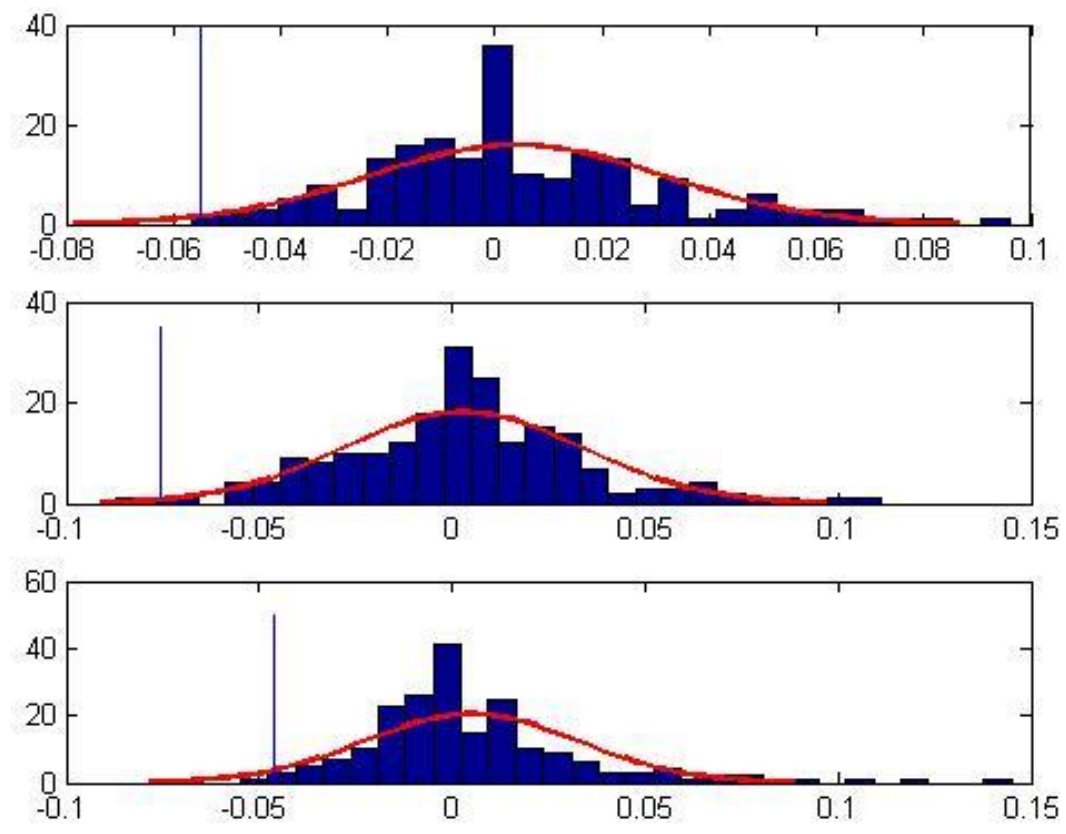

Figure 5: Maximum Likelihood Function Bank Mandiri, Bank BRI and Bank BNI in 2010
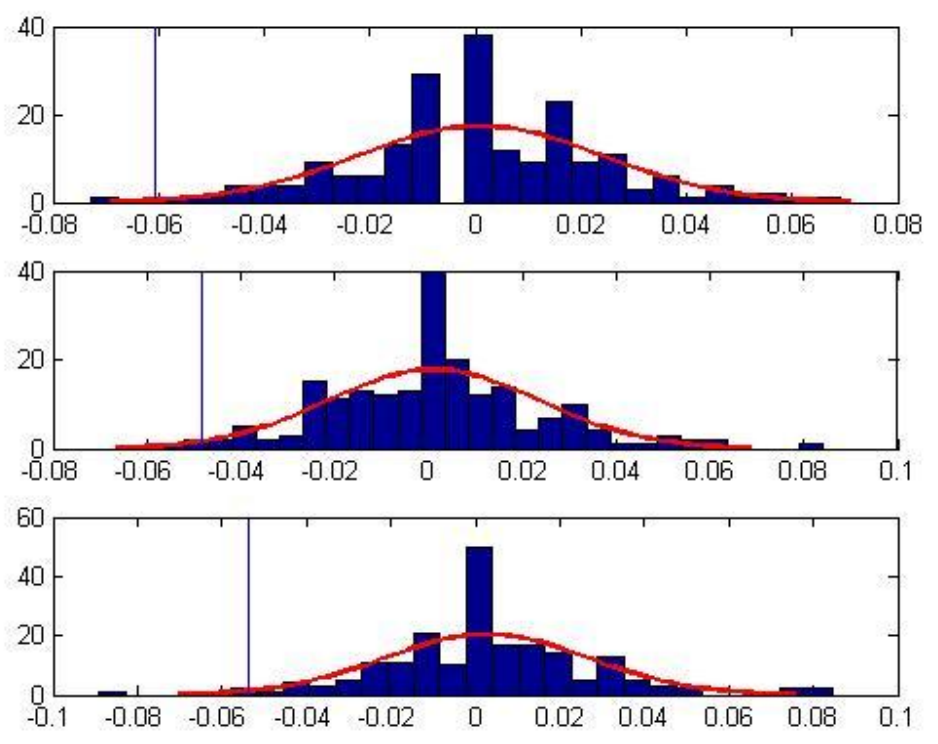
Figure 6: Maximum Likelihood Function Bank Mandiri, Bank BRI and Bank BNI in 2011
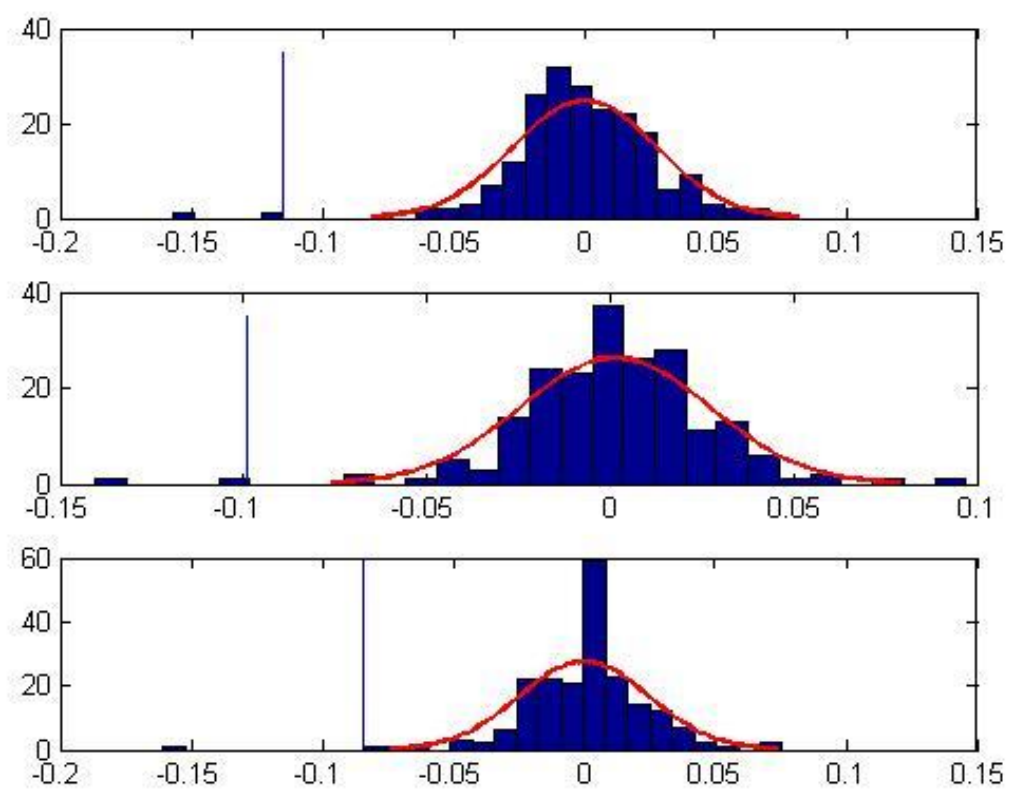

In Figure 4, we can see that the tail on the right side is longer than the left side (the bulk of the values lie to the left of the mean = positively skewed distribution). Positively skewed distribution is caused by many of data that increase the mean $(X>M d>M o)$. So that many frequency of return will be faced by the investor for Bank BRI in 2009. This is shown in return that more than 0.1 and the risk less than -0.1. Positive and negative for the distribution is known by (7). The modus at Bank BRI in 2009 is 0.0025 so the coefficient of skewness is 0.0064 . This positive number means the curve has positively skewed distribution. The normal curve with one tail test shows that the rejection region is $\alpha(1 \%)$. Meanwhile at data return that shown in the blue histogram has the rejection regions of Value at Risk is -0.0754 at $1 \%$ significant level. To fulfill the purpose of maximum likelihood that observe a sample of data and have a distribution model in mind relates to its ability to ascertain the most likely parameter values that could generate the observed data, the indicator is Value at Risk $=\alpha$. At figure 4 at Bank BRI is shown that value at risk $=\alpha$. with the green line and explain that the assumption model is appropriate with data return at Bank BRI in 2009.

\section{Conclusion}

Empirical results demonstrate that the less of Value at Risk by historical simulation in each year is at Bank BNI in 2009, at Bank BRI in 2010 and at Bank BNI in 2011. Using maximum likelihood method in the estimation of VaR has certain appropriates values of $\alpha$. compared with the normal curve in 2009-2010. However, in 2011 the estimation of VaR hasn't certain appropriates value of $\alpha$ compared with the normal curve. The empirical results show that using a historical simulation in the estimation of VaR has certain advantages such as using actual historical data that make the result accurate and easy for the investors to understand the risk of their business. Consequently, investors are encouraged to use historical simulation to estimate VaR of asset return.

\section{References}

Bank Indonesia. (2010). Global crisis and rescue Indonesian banking system. Retrieved 8 October 2012 from http://www.bi.go.id/NR/rdonlyres/24C9500A-C0Cf

4BB3954DD2997AD865B3/18659/krisisglobaldampenyelamatansistemperbankanindonesia.pdf.

Christoffersen, P., Hahn, J. \& Inoue, A. (2001). Testing And Comparing Value-At-Risk Measures. CIRANO, 1-18. Danielsson, J. (2011). Financial Risk Forecasting (1 $1^{\text {st }}$ ed). Wiley.

Hull, J. C. (2012). Option, Futures, and Other Derivatives ( $8^{\text {th }}$ ed). Pearson. 
Jorion, P. (2007). Value at Risk (3rd ed). McGraw-Hill.

Krause, A. (2003). Exploring the limitations of value at risk: how good is it in practice?. The Journal Of Risk Finance, 2, 19-27.

Sartono, R. A. \& Setiawan, A. A. (2006). Var optimal portfolio: a comparison between markowitz method and mean absolute deviation. Jurnal Siasat Bisnis, 11, 37-50.

Stambaugh, F. (1996). Risk and Value at Risk. European Management Journal, 14, 612-621.

Surya, Y. \& Situngkir, H. (2006). Value at risk that takes into account the statistical properties of the return distribution. Munich personal RePEc Archive, 5, 895, 1-10. 